\title{
A ANGÚSTIA DE (ser) E SUA INTERFACE COM A EXISTÊNCIA E A MORTE
}

DOI: $10.22289 / 2446-922 X . V 2 N 2 A 3$

\author{
Olinta de Oliveira Guimarães ${ }^{1}$
}

Cátia de Castro Dias

\section{RESUMO}

A existência é a presença do homem no mundo, senhor de sua singularidade e consciência, responsável por suas escolhas. Neste trabalho buscou-se destacar a angústia do homem frente a sua existência como senhor de suas escolhas, abordando também sua consciência de finitude. O presente artigo foi realizado através de revisão da literatura, buscando-se informações em artigos, monografias, dissertações e livros, tanto em ambiente virtual quanto físico. A partir das pesquisas realizadas, pode-se verificar que os pensadores existencialistas buscam mostrar as angústias do ser humano, seus dilemas, conflitos, mas, sempre mostrando o valor da vida, seu humanismo. O ser humano existe, está presente no mundo, sozinho, sem ninguém para ampara-lo. $O$ ato de fazer escolhas causa desconforto, pois independente de sua tomada de decisão, ele não deixa de perder algo e é esse medo que lhe gera angústia. Durante sua existência o indivíduo vivencia diversos tipos de perdas, sejam elas materiais ou físicas, porém, a morte, o fim da existência é o que traz um significado doloroso, coloca o homem enquanto ser vigoroso e autônomo diante de algo inevitável, faz com que ele pense a respeito de sua finitude e daqueles que ama.

Palavras chaves: Existencialismo, Angústia, Homem, Morte.

\section{ABSTRACT}

Existentialism can be characterized as a philosophical movement that began in the nineteenth and twentieth century, whose representatives include: Hurssel, Kierkegaard, Heidegger, Friedrich Nietzsche, Jean Paul Sartre, among others. Existentialist thinkers seek to show the anguish of human beings, their dilemmas, conflicts, but always showing the value of life, his humanism. The human being exists, is present in the world, alone, with no one to support him. Existence is the presence of man in the world, master of its uniqueness and awareness, responsible for their choices. This paper was developed through a bibliographic research, with the aim to address through an existential and humanistic perspective, the concept of man's existence, front anguish to the world. The act of making choices causes discomfort, because regardless of their decision-making, he does not fail to miss something and it is this fear that creates her anguish. During its existence the individual experiences different types of losses, whether material or physical, however, the death, the end of existence is what brings a painful meaning, places the man as a vigorous, autonomous before inevitable causes he thinks about his finitude and those you love.

Key words: Existencialism, Anguish, Man, Death.

\footnotetext{
1Endereço eletrônico de contato: olintacp@hotmail.com
}

Recebido em 08/09/2016. Aprovado pelo Conselho Editorial e aceito para publicação em 29/09/2016. 


\section{INTRODUÇÃO}

"O existencialismo é um humanismo. Tentaremos explicitar em que sentido o entendemos. De qualquer modo, o que podemos desde já afirmar é que concebemos o existencialismo como uma doutrina que torna a vida humana possível." (1)

O homem é o único responsável por ele mesmo, não existe nada que pode ampará-lo em seu trajeto. O existencialismo contribui para a compreensão da vida, da existência, do ser-no-mundo como dono de suas escolhas que terminam por influenciar aqueles que estão próximos. Essa responsabilidade por si mesmo e pelo outro acaba gerando um sentimento de angústia, não adianta o homem buscar desculpa, agir de má-fé, não existe nada esperando após sua morte. Isso acaba gerando um sentimento de angústia, desamparo frente ao mundo, à vida e suas escolhas.A literatura existencialista contribui para a compreensão da angústia que pode ser evidenciada na citação de Camus em O Estrangeiro:

Conservei ainda algumas imagens deste dia: (...) o desmaio do Perez (dir-se-ia um boneco partido), a terra cor de sangue que atiravam para cima do caixão da mãe, a carne branca das raízes que se lhes juntavam, ainda mais gente, vozes, a aldeia, a espera diante de um café, o incessante roncar do motor, e a minha alegria quando o autocarro entrou no ninho de luzes de Argel e que pensei que me ia deitar e dormir durante doze horas. (2)

De onde vem então, a angústia do ser humano frente às perdas e a morte? Quando retrocedemos no tempo e estudamos culturas e povos antigos, temos a impressão de que o homem sempre abominou a morte e, provavelmente, sempre a repelirá. (3)

No livro do escritor e psicólogo Viktor Frank, escrito depois de sua experiência enquanto prisioneiro no campo de concentração durante a Segunda Guerra, cujos escritos retratam o dilema humano diante da morte. Mesmo sabendo que o fim da existência rondava a todos, diante de tantas mortes o homem não sucumbe, continua tentando viver, sobreviver, mesmo nos martírios de um campo de concentração.

Atrás do galpão de enfermos, um barracão de chão batido em que se amontoavam cerca de cinquenta companheiros com febre alta, delirantes, havia um cantinho sossegado, onde a cerca dupla de arame farpado que circunda o campo formava uma esquina. Ali tinham improvisado com algumas estacas e galhos uma espécie de barraca na qual se jogava a meia dúzia de cadáveres "produzidos" diariamente em nosso campo - que era considerado pequeno! Havia ali no chão uma abertura de acesso à canalização subterrânea, fechada com tampa de madeira. Nesta eu me sentava, sempre que me podiam dispensar por

Rev. Psicol Saúde e Debate. Jan., 2017:2(2):42-57. 
alguns minutos como médico no galpão. Aninhado ali, eu contemplava por entre a vinheta obrigatória do arame farpado - os vastos campos verdejantes e floridos, as distantes colinas azuis da paisagem bávara. Ali eu sonhava os sonhos de minha saudade e enviava meus pensamentos para bem longe, para o norte e nordeste, onde supunha pessoas amadas. Agora, porém, somente enxergava ali nuvens de perfil estranho e bizarro. Atirados a meu lado os cadáveres cheios de piolhos não chegavam a me perturbar. (4)

Ao ser comunicado de que é portador de uma doença terminal, o paciente passa pelos estágios de negação da doença, raiva, barganha, depressão, aceitação e esperança, sendo esta a que está presente em todos os estágios. Nas situações em que os pacientes encontram-se em estado terminal, geralmente, podem ser verificados casos em que a morte é precedida de sofrimento físico e psíquico e, ao mesmo tempo, verifica-se também, o despreparo de grande parte dos profissionais de saúde nos hospitais, para o atendimento ao doente nessas condições, cuja morte é iminente, tal despreparo pode incorrer em problemas éticos para a equipe hospitalar. (3)

A morte constitui uma limitação do homem. "O 'fim' do ser-no-mundo é a morte. Esse fim, que pertence ao poder-ser, isto é, à existência, limita e determina a totalidade cada vez possível do Dasein." (5)

Conforme Heidegger:

Assim como a angústia, "a antecipação da morte singulariza o ser-aí". Desse modo, a morte permite basicamente: 1) uma consciência de toda a existência (passado, presente, futuro) e, por isso, também será por ela que o ser irá encontrar a sua verdade no tempo. 2) assumir individualmente a existência, já que a experiência da morte é sempre apenas minha. ${ }^{(5)}$

A angústia assume em Heidegger um cunho existencial essencialmente humano, pois somente o homem se angustia e tem uma compreensão do ser.

É por meio da angústia, estrutura fundamental que dá condição ao Dasein rumar à autenticidade, que o mesmo pode se livrar do peso imposto pela cotidianeidade e o impessoal: "Só na angústia subsiste a possibilidade de uma abertura privilegiada na medida em que ela singulariza. Essa singularização retira o ser-aí de sua decadência, e lhe revela a autenticidade e inautenticidade como possibilidades de seu ser." (5)

O objetivo desse trabalho é pesquisar a respeito dos aspectos que permeiam a existência do homem, os fatores que o angustiam e a consciência de ser para a morte, 
abordando conceitos fenomenológico-existenciais. Pretende-se promover uma reflexão através da visão de que a sociedade prepara o homem para a vida, para estar em constante movimento, deixando-o despreparado para a morte.

\section{MÉTODOS}

O trabalho é do tipo qualitativo, descritivo de revisão da literatura e de natureza conceitual. Em cuja pesquisa qualitativa buscou-se perceber a totalidade existencial do ser pautada nos pensamentos de autores como: Hurssel, Kierkegaard, Heidegger, Friederich Nietzsche, Jean Paul Sartre, e também na literatura existencial e humanista. O levantamento do material deu-se por meio da inclusão de artigos publicados no período de 2000 e 2015 no idioma português e dados anteriores ao referido período devido a literatura existencialista estar embasada por autores de séculos passados, disponíveis nas bases de dados do Scielo, Bireme, Lilacs e Pepsic. A busca deu-se por meio do cruzamento das palavras: existencialismo, angústia, homem e morte.

\section{OS PRINCIPAIS CONCEITOS EXISTENCIALISTAS}

Sartre sabiamente dizia que somente a liberdade é determinante, ou seja, o homem se cria de forma livre e situada e sua consciência é sempre consciência de algo, desta forma, é responsabilizado pelo que é e pelos valores que cria. ${ }^{(6)}$

Há pelo menos um ser no qual a existência precede a essência, um ser que existe antes de poder ser definido por qualquer conceito: este ser é o homem. O que significa dizer que a existência precede a essência? Significa que, em primeira instância, o homem existe, encontra a si mesmo, surge no mundo e só posteriormente se define. De início não é nada: só posteriormente será alguma coisa e será aquilo que ele fizer de si mesmo e é esse o primeiro princípio do existencialismo. ${ }^{(6)}$

O existencialismo surge como uma forma de analisar a existência, o modo de ser do homem no mundo, questiona esse mundo sem pressupor o ser como constituído. 
Abarca a interpretação do modo como o ser se relaciona com o mundo e as influências que esse mundo exerce sobre o próprio homem. (7)

Para investigar o homem enquanto aquele que possui sempre uma compreensão de ser impõe-se uma analítica existencial, que tem como tarefa explorar a conexão das estruturas que definem a existência do Dasein, a saber, os existenciais. $O$ método da analítica existencial é buscado também na Fenomenologia, isto é, no método fenomenológico: que vai diretamente ao fenômeno, procedendo à sua análise, pondo a claro o modo como se dá a mesmo, parte do homem de fato, deixa que ele se manifeste tal qual é, e procura compreender, sua manifestação. ${ }^{(5)}$

O indivíduo é um ser totalmente livre e para que se dê tal liberdade e o ser humano surja no mundo sem essência é preciso que nenhuma inteligência o tenha pensado anteriormente, dessa forma, a existência de Deus como um criador deve ser eliminada, pois se Ele instituísse a natureza do indivíduo, este já nasceria predeterminado a materializar sua essência que já teria sido elaborada antes mesmo dele vir ao mundo, sem Deus para agir como determinante do modo de vida do homem, ele se encontra livre para se criar. ${ }^{(8)}$

O ser existente e o mundo vivem diante de uma tensão, são dialeticamente distintos e não podem se unir e nem se separar, porém, implicam-se mutuamente. A existência é incondicionada, não pode ser transmitida a outrem e é um privilégio do homem, portador de uma interioridade que só ele sente,ser para-si.(9)

O Dasein é sempre lançado no mundo. Ele assume esse ser-lançado no projeto. Sendo consciente da sua situação de abandono, pois ser-ai - significa ser lançado no mundo para existir. Uma vez consciente de sua liberdade e colocado diante de suas possibilidades de escolhas, o sentimento da angústia é inevitável, mas são elas que darão significado à existência individual e sendo assim cabe a cada um, escolher também, individualmente. É a partir delas que o projeto vai se concretizando ou então, perdendo-se. ${ }^{(5)}$ O fato de existir faz do homem um ser de escolhas, que precisa decidir sobre os caminhos que irá percorrer e essa possibilidade de escolher instaura em sua existência a angústia, tema que se tornou importante dentro dafilosofia e existencialismo através de seu precursor Kierkegaard. (9)

O homem é tão somente, não apenas como ele se concebe, mas também como ele se quer; como ele se concebe após a existência, como ele se quer após esse impulso para a existência. O homem nada mais é do que aquilo que ele faz de si mesmo. (1) 
A oportunidade de escolha e o conceito de possibilidade revelam dois caminhos que poderão ser vivenciados pelo homem, aquele em que algo se concretizará e o segundo caminho em que aquilo que se espera poderá não acontecer. São duas vias que não oferecem garantias antecipadas ao homem e lhe geram um sentimento de náusea por encontrar-se em meio a possibilidades que não lhe oferecem critérios pré-definidos para que o mesmo realize suas escolhas. ${ }^{(8)}$

A angústia não pode ser entendida como uma forma de inação do homem, pelo contrário, a responsabilidade por ter que decidir e o desconforto causado por tal sentimento não podem impedi-lo de fazer suas escolhas, pois se assim o fizesse, seria um covarde, a angústia é uma parte constitutiva da própria ação do homem. (1)

Sou responsável por tudo, de fato, exceto por minha responsabilidade mesmo, pois não sou o fundamento do meu ser. Portanto, tudo se passa como se eu estivesse coagido a ser responsável. Sou abandonado no mundo, não no sentido de que permanecesse desamparado e passivo em um universo hostil, tal como a tábua que flutua sobre a água; mas, ao contrário, no sentido de que me deparo subitamente sozinho e sem ajuda, comprometido em um mundo pelo qual sou inteiramente responsável, sem poder, por mais que tente livrar-me um instante sequer, desta responsabilidade, pois sou responsável até mesmo pelo meu próprio desejo de livrar-me das responsabilidades. ${ }^{(10)}$

O existencialista afirma que o homem é angústia, ele não é apenas aquilo que escolheu ser, ele deve obedecer a leis e ao mesmo tempo em que escolhe a si mesmo não pode abrir mão do restante da humanidade, não há uma forma dele escapar da convivência com o todo, com os outros seres humanos e deixar de lado o sentimento total de profunda responsabilidade. $O$ homem é posto diante de certos dilemas e a partir do momento que assume o encargo de tomar uma decisão que influencie a vida de outras pessoas, mesmo que a ordem venha de um ser superior a decisão final é sua, ele a toma sozinho e aí surge a angústia, porém, uma angústia que não lhe impede de agir, mas que constitui a condição de sua ação. (1)

Junto ao conceito de angústia surge o desespero, momento em que o homem como ser finito deseja tornar-se infinito. O desespero aparece quando o espírito quer a síntese do finito, ou seja, da matéria com o infinito, que é o espírito para fazer surgir o eu existencial. (9)

Tornar-se a si próprio é tornar-se concreto, ato irrealizável tanto no finito quanto infinito, pois o concreto é uma síntese e a evolução consiste em afastar-se de si próprio 
buscando o infinito. O eu que não se torna ele próprio permanece, conscientemente ou não em um estado de desespero. (11)

Cada ser escolhe perante os outros e se escolhe perante os outros, algumas escolhas são embasadas no erro e outras na verdade. O homem como um ser livre para escolher, a partir do momento que se refugia atrás de desculpas, torna-se um homem de má-fé e esta é uma tentativa frustrada de negar a liberdade, pois o homem só pode negá-la sendo livre para tal. ${ }^{(1)}$

Se a má-fé é possível, deve-se a que constitui a ameaça imediata e permanente de todo projeto do ser humano, ao fato de a consciência esconder em seu ser um permanente risco de má-fé. E a origem desse risco é que a consciência, ao mesmo tempo e em seu ser, é o que não é e não é o que é. (10)

Quando o homem deixa de se refugiar e assume sua responsabilidade perante o mundo e os outros, aceita sua realidade e reconhece-se como responsável por suas escolhas demonstrando coerência em seus atos, aí sim demonstra boa fé. Um homem de boa fé volta seus atos para a procura da liberdade enquanto tal. (1)

\section{O EXISTIR, A ANGÚSTIA E O NADA}

Angústia, sentimento ligado ao existir, inevitável ao homem que se encontra a todo instante diante da tensão daquilo que ele é e o que ele não pode ser ou evitar que seja. Quando tem coragem de enfrentar tal sentimento e fazer escolhas para mudar seu destino assume o risco de obter êxitos ou fracassar diante de seus objetivos. É na superação de suas dificuldades que ele irá adquirir uma compreensão mais dinâmica de sua existência e se tornará mais amadurecido em relação à sua condição de ser-no-mundo. (12)

O angustiar-se abre, de maneira originária e direta, o mundo como mundo. Não é primeiro a reflexão que abstrai do ente intramundano para então só pensar o mundo e, em consequência, surgir a angústia nesse confronto. Ao contrário, enquanto modo da disposição, é a angústia que pela primeira vez abre o mundo como mundo. ${ }^{(13)}$

A vida é angustiosa, pois tem duas facetas, de um lado encontra-se o desejo de viver, de desfrutar daquilo que ela pode oferecer, de continuar sendo, para que o futuro 
um dia seja presente. De outro lado, o anseio de ser, leva à consciência da possibilidade de não ser, o temor de deixar de ser, o temor do nada e aí encontra-se a angústia, pois esse nada amedronta o homem. Ele se torna um eterno viajante buscando dar sentido à sua vida, para então, construir uma existência autêntica. ${ }^{(9)}$

O porquê a angústia se angustia não é um modo determinado de ser é uma possibilidade do ser-aí. A ameaça é ela mesma indeterminada, não chegando, portanto, a penetrar como ameaça neste ou naquele poder-ser concreto e de fato. A angústia se angustia pelo próprio serno-mundo (...). o mundo não é mais capaz de oferecer alguma coisa nem sequer a co-presença dos outros. A angústia retira, pois, do seraí a possibilidade de, na decadência, compreender a si mesmo a partir do mundo e na interpretação pública. ${ }^{(5)}$

O homem por vezes encontra-se angustiado, mas não consegue definir o porquê de tal sentimento, encontra-se suspenso na angústia e muitas vezes nem a percebe, pois ela Ihe oferece uma estranha tranquilidade. ${ }^{(14)}$

A alma é uma paisagem, ou melhor, paisagens. Paisagens são feitas com campos, flores, montanhas, rios, mares, nuvens - "coisas" que existem fora de nós, que os sentidos percebem e nós lhes damos nomes. As paisagens da alma, entretanto, não são feitas de "coisas". São feitas de sentimentos. E os sentimentos, não temos como dizêlos, os sentidos não conseguem fotografá-los. Então um artista que mora dentro da gente, o tal do inconsciente, lança mão de um artifício: ele veste os sentimentos da paisagem de dentro com as coisas da paisagem de fora. ${ }^{(15)}$

Assim é a angústia, um sentimento gerador de desconforto, um aperto no peito do homem, que muitas vezes não é passível de explicações, apenas acontece e gera alguma transformação, seja o movendo para produzir algo ou limitando seu existir. A palavra angústia designa sufoco, um estado em que o indivíduo se encontra dominado perante um perigo que está iminente e inevitável e que em parte ainda não foi experimentado, é exclusivamente interna e não tem um objeto específico e concreto. ${ }^{(9)}$

$\mathrm{Na}$ angústia o saber cai por terra e quando o homem se encontra à beira do precipício, se agarra às verdades consideradas incontestáveis do conhecimento que possui, na tentativa de diminuir o desconforto causado por experimentar tal sentimento. ${ }^{(16)}$

O homem é um ser que se encontra lançado no mundo e quanto mais vive, menos tem a viver. Tem na angústia uma presença constante em sua vida, à medida que volta seu olhar para si mesmo e conclui que caminha solitário para um destino inevitável e individual que é sua própria morte. (17) 
Entre viver e morrer há um caminho a ser percorrido, há uma história a ser escrita pelo homem. Cada ser que nasce, encontra-se destinado a viver, conhecer o mundo em suas diferentes facetas, tropeçar e se reerguer. A consciência de finitude faz com que o homem olhe para trás, reveja sua história e por vezes, sinta saudade do que foi, orgulho do que é e ânsia pelo que poderá vir a ser e aí mora a angústia. No momento em que o sofrimento por deixar de existir e abandonar todo esse percurso se faz presente, a antecipação do sofrimento faz com que o homem perca o gosto pela vida e é preciso compreender que cada coisa tem seu tempo. ${ }^{(18)}$

Albert Camus em sua obra O Mito de Sísifo, retrata a morte no âmbito do suicídio, a morte tida como voluntária, que se prepara no silêncio do coração do homem que quando chega ao ponto de colocar fim à sua existência o faz sem refletir, comete o ato em um ímpeto de sofrimento incontrolável e é como se confessasse que foi ultrapassado pela vida ou que não conseguiu compreendê-la. ${ }^{(19)}$

Seria o suicídio uma forma de escapar de uma existência sem sentido? O suicídio seria a aceitação de seus limites, um salto para o seu próprio futuro, uma precipitação em direção à sua única certeza. A morte é desprezada pelo homem, ainda que saiba que este é o destino de todo ser vivo. Concluir que a vida não vale a pena ser vivida porque um dia terá fim é um absurdo, viver é uma experiência que deve ser desfrutada plenamente. Viver é fazer viver o absurdo e desprezar seu destino. (19)

A angústia coloca o homem diante de si mesmo, faz com que ele reflita sobre sua condição no mundo, preparando-o e anunciando uma ruptura necessária, a de fazer uma escolha para realizar o próprio eu, é preciso estar preparado para lidar com os sentimentos inerentes a essa necessidade de escolher e lidar com as consequências, tanto positivas quanto negativas de tal decisão. (20)

Os questionamentos essenciais acerca da vida que surgem para o homem são responsáveis pela supressão ou crescimento da paixão pelo viver e a forma como ele percebe sua existência poderá levá-lo a repudiar a própria vida e o suicídio é uma demonstração da falta de motivação para continuar. Porém, há ainda outro aspecto humano relacionado ao apego pela vida, mesmo em momentos de crise e aflição o homem ainda possui a vontade de continuar vivo e enfrentar as barreiras que são impostas a todo o momento em seu caminho. Desta forma, a angústia frente à morte, estaria relacionada ao sentimento de perda e de temor do próprio deixar de existir. (21)

\section{O OLHAR DO HOMEM FRENTE ÀS PERDAS E A MORTE}

Rev. Psicol Saúde e Debate. Jan., 2017:2(2):42-57. 
A morte está sempre presente em nossas vidas. Pode ser em noticiários, na violência do dia-a-dia, na perda de um familiar. O corpo é finito e a morte a constatação dessa realidade.

[...] nosso corpo é para nós, porque somos escolha, e ser é, para nós, escolher-nos. Mesmo esta invalidez de que padeço, pelo próprio fato de vivê-la, eu a assumi, e a transcendo rumo a meus próprios projetos, constituo-a como o obstáculo necessáriopara meu ser; não posso ser enfermo sem me escolher inválido, ou seja, sem escolher a maneira como constituo minha invalidez (como "intolerável", "humilhante", "a ser dissimulada", "a ser revelada a todos", "objeto de orgulho", "justificativa para meus fracassos" etc.). Mas este corpo inapreensível é precisamente a necessidade de que haja uma escolha, ou seja, a necessidade de que eu não seja tudo ao mesmo tempo. Nesse sentido, minha finitude é condição de minha liberdade, pois não há liberdade sem escolha, e, assim como o corpo condiciona a consciência como pura consciência do mundo, minha finitude torna a consciência possível até mesmo em sua própria liberdade. ${ }^{(10)}$

O homem só não está isento de fazer escolhas, mesmo não escolhendo nada, já é uma escolha. Ele está fadado à liberdade, assim como não está isento da morte, da perda de pessoas próximas ao seu convívio. A dor, o sofrimento, a morte, assim como a liberdade acompanham a existência humana e o existencialismo proporciona uma melhor compreensão dessa realidade. ${ }^{(12)}$

O homem está em contato diariamente com situações relacionadas à morte, seja através de jornais, revistas, televisão, dentre outros meios de comunicação e por vezes elas estão distantes de sua realidade o que o faz pensar sobre como ele reagiria se algo acontecesse com as pessoas próximas a ele, seus familiares, amigos e até mesmo consigo e qual seria sua reação. ${ }^{(22)}$

A dor da perda, o sofrimento e o luto não estão relacionados apenas à morte, mas também a situações como, fracassos do dia a dia, frustrações profissionais, términos de relacionamentos, desejos irrealizados, vivência de alguma doença grave, dentre outras. Todas essas situações geram impacto na vida do indivíduo e lhe provocam uma reflexão a respeito do sentido da vida, em que é preciso se reinventar. (22)

Durante sua existência, o homem passa por diversas perdas e tem que aprender a lidar com elas, transformar seu modo de vida e se readaptar diante daquilo que possui em determinado período. Porém, algumas delas são mais difíceis de serem superadas. A partir do momento em que se vivencia a perda de autonomia, devido a alguma condição médica, a deterioração física de um ser amado, a consciência da proximidade da morte, eis 
que surgem os sentimentos de angústia e de impotência, por não se possuir meios de impedir que isso aconteça, visto que a morte é uma certeza e chega para todos sem avisar. (23)

O processo de adoecimento pode envolver situações de isolamento, sensação de abandono e problemas somáticos. Questões que trazem para a família e seus entes queridos uma carga emocional negativa. ${ }^{(14)}$

A morte enquanto fenômeno encontra-se carregada de valores e significações do ponto de vista sócio-histórico-cultural, quando encarada como um limite ajuda o homem a crescer, porém, e comumente é vivenciada como dor, perda de funções do corpo, corte e separação daqueles que se ama, solidão e tristeza. Assim sendo, está carregada de significações negativas e angustiantes, em que o indivíduo caminha para um fato desconhecido o qual é experimentado sozinho. (23)

As mudanças, alterações na vida do homem, não têm data nem hora certa para acontecer, os fatos tristes ou alegres, perdas e ganhos são imprevisíveis. A partir do momento em que uma perda é interpretada como negativa pelo indivíduo, esta é considerada como uma morte simbólica. As constantes perdas e a elaboração do luto servem como um aprendizado voltado para o saber lidar com a morte e a própria finitude. ${ }^{(24)}$

Existem muitas razões para que o homem evite encarar a realidade da morte e uma delas é que morrer é considerado algo triste sob diversos aspectos, é solitário, mecânico e desumano dependendo da situação em que se finda a vida. ${ }^{(3)}$

[...] a vida limita-se com vida, torna-se, tal como o mundo einsteiniano, "finita, mas ilimitada"; a morte converte-se no sentido da vida, assim como o acorde de resolução é osentido da melodia; nada há de milagroso nisso: a morte é um termo da série considerada, e, como se sabe, cada termo de uma série está sempre presente a todos os termos da mesma. Mas a morte assim recuperada não permanece simplesmente humana, mas torna-se minha; ao interiorizar-se, ela se individualiza; já não é mais o grande incognoscível que limita o humano, mas o fenômeno de minha vida pessoal que faz desta vida uma vida única, ou seja, uma vida que não recomeça, uma vida na qual não podemos ter uma segunda chance. Com isso, torno-me responsável por minha morte, tanto quanto por minha vida. Responsável, não pelo fenômeno empírico e contingente de meu trespasse, mas por esse caráter de finitude que faz com que minha vida, comominha morte, seja minha vida. ${ }^{(10)}$

Com os avanços tecnológicos e da medicina, buscam-se cada vez mais formas de evitar a morte, seja através de medicações, procedimentos cirúrgicos, métodos por vezes invasivos e dolorosos. Quando a medicina se depara com a impossibilidade de fazer algo por 
um indivíduo, surge a indignação por parte de familiares e até mesmo do próprio paciente, nesse momento a aceitação da morte torna-se difícil, porém, necessária. (25)

Pacientes terminais vivenciam alguns estágios até que consigam aceitar sua morte, podem negar sua condição, sentir raiva da situação em que se encontram e comumente tentam barganhar com Deus em uma tentativa de se tornarem melhores caso voltem a ser saudáveis. Quando não conseguem negar mais sua condição surge o estágio da depressão no qual o indivíduo se vê obrigado a aprender a lidar com sua finitude, e é no momento em que ele cessa sua luta e começa a se preparar para a morte que surge a aceitação, estágio que nem sempre é atingido por todos, visto que alguns se mantêm agarrados à esperança de cura até o último momento. ${ }^{(3)}$

Durante todos os estágios o paciente mantém viva a esperança, e até mesmo as pessoas que já estão conformadas com sua doença deixam um espaço para tal sentimento e é preciso deixar claro para o indivíduo de que ele está recebendo tratamento adequado e sendo feito o possível para salvá-lo. O indivíduo precisa perceber que mesmo que não haja cura para sua doença ele não será abandonado pela equipe médica e por seus familiares. ${ }^{(3)}$

Trabalhar a dor da perda é importante para que o indivíduo não prolongue o processo de luto, pois evitar o sofrimento e buscar refúgio em outros lugares ou pessoas que o distanciem dessa vivência pode piorar sua situação emocional, visto que em algum momento será impossível não se deparar com essa condição novamente. (22)

Quando um vínculo é rompido, o indivíduo busca recursos para elaborar o luto na qualidade do vínculo anteriormente existente. Se o vínculo básico foi seguro, o sujeito terá sua autoconfiança e autoestima desenvolvidas, viabilizando a elaboração do luto com consequente possibilidade de firmar novos vínculos. Se o vínculo básico foi ansioso, provavelmente a confiança e a autoestima não se desenvolverão de forma consistente. Ao vivenciar um rompimento de vínculo por morte, os recursos internos não serão suficientes para superar adequadamente a perda e encontrar novas possibilidades de vínculos, podendo ocorrer o chamado luto patológico, atualmente denominado luto complicado. (26)

As vivências relativas à morte precisam ser elaboradas pelo indivíduo the permitindo um processo de ressignificação da vida com a possibilidade de novos projetos. Cada um vivenciará o luto à sua maneira, para alguns, sua elaboração poderá ocorrer de forma mais rápida, para outros ele se dará lenta e dolorosamente, o que pode fazer com que o indivíduo veja a necessidade de buscar ajuda de terceiros. ${ }^{(6)}$

O luto vivido em decorrência da morte de um ente querido além de ser uma experiência dolorosa, também traz a consciência da própria morte, de sua inevitabilidade e irreversibilidade. Os aspectos ontológicos contribuem para tornar seu enfrentamento difícil e 
se apresentar como situações reveladoras de conflitos que ocorreram no passado do indivíduo e que diante de tal situação de estresse podem encontrar espaço para uma (re)significação. (27)

Diante da perda, o enlutado pode sentir a necessidade de substituir a pessoa que partiu, colocar algo ou alguém no lugar com o intuito de diminuir seu sofrimento. Em determinadas situações o indivíduo voltará a praticar hábitos de infância que lhe remetem à segurança dos cuidados de seus pais. Não existe um tempo determinado para a elaboração do luto, cada um vivenciará essa fase de uma maneira distinta. (22)

Temos uma capacidade quase infinita de suportar a dor, desde que haja esperança. Diz-se que a esperança é a última que morre, mas o certo seria dizer: a penúltima. Há uma morte que acontece antes da morte. Quando se conclui que não há mais razões para viver. Quando morrem as razões para viver, entram em cena as razões para morrer. (15)

O mesmo autor evidencia que o processo de elaboração do luto é também um período de reinvenção, de mudança de hábitos, uma busca por novas experiências. É um processo de ressignificação da própria vida no qual o indivíduo deverá se reerguer para prosseguir após a perda sofrida. Tais ações precisam estar amparadas pelo sentimento de esperança, para que a dor não seja limitante, e que o continuar existindo seja prazeroso e continue fazendo sentido. ${ }^{(15,29)}$

Os indivíduos que vivenciam o luto, a perda, a atuação do psicólogo ajuda nessa elaboração da esperança. Assim como o pensamento existencialista não cria conjecturas, fabulações, de uma realidade inexistente.

Atualmente a Psicologia ganha espaço na sociedade. Entende-se que este ganho vem acompanhado de um compromisso social, de construção de práticas comprometidas com uma sociedade mais justa. Esta ciência precisa assumir novas exigências, suas práticas não se limitam mais somente a consultórios e a serviços de saúde mental. 0 psicólogo não é mais meramente um avaliador. É um profissional das ciências humanas que se enquadra na área da saúde, porque não tem como haver saúde sem humanização. ${ }^{(30)}$

A psicologia fenomenológica-existencial ajuda nessa compreensão desse caminhar, nesse trajeto do homem, seus dilemas, anseios, angústias diante da vida, de suas escolhas, perdas e morte. O existencialismo é realmente uma filosofia humanista, porque retrata o ser humano em toda a sua complexidade. 


\section{CONSIDERAÇÕES FINAIS}

O homem surge no mundo como uma espécie de folha em branco, é livre para fazer suas escolhas e através dos caminhos pelos quais irá passar e de suas diferentes vivências ele formará sua essência. A todo o momento sofre influências externas e também influencia outros indivíduos, havendo uma constante troca de experiências entre homem e sociedade.

A aquisição de responsabilidades e a consciência do poder de suas decisões coloca o homem frente à angústia de ter que optar por um caminho dentre tantos que o mundo Ihe oferece, pois, cada escolha pressupõe uma perda e perder gera incômodo. Seja perder uma oportunidade, um amigo, um amor, autonomia, vitalidade e a própria vida. Eis o ponto chave e causador de grande angústia, a presença de uma perda irrecuperável, o deixar de existir.

O homem enquanto ser para a morte, deveria estar acostumado ao curso natural da vida, em que os indivíduos nascem, crescem e em algum momento indeterminado morrem. Quando a noção de perda e da própria finitude se aproxima da consciência do homem, então este Ihe gera sofrimento e grande desconforto. O indivíduo precisa aprender a lidar com tais sentimentos para que não inicie um processo de adoecimento.

O processo de elaboração das perdas é lento e por vezes árduo, exigindo do indivíduo capacidade de resiliência e a presença de pessoas importantes que lhe auxiliarão a compreender tal questão e a vivenciá-la da melhor forma possível.

\section{REFERÊNCIAS}

1. Sartre, JP. O existencialismo é um humanismo. Seleção de textos de José Américo Mota Pessanha. Tradução de Rita Correia Guedes, Luiz Roberto Salinas Forte e Bento Prado Júnior. 3 ed. São Paulo: Nova Cultural; 1987.

2. Camus A. O estrangeiro. Tradução de Valerie Rumjanek. 16 ed. Rio de Janeiro: Record; 1977.

3. Kubler-Ross E. Sobre a morte e o morrer. Martins Fontes: São Paulo; 2005.

4. Frankl VE. Em busca de sentido. Tradução de Carlos C. Aveline. Viena; 1984.

Rev. Psicol Saúde e Debate. Jan., 2017:2(2):42-57. 
5. Heidegger M. Ser e Tempo. Tradução de Márcia de Sá Cavalcante. 3 ed. Petrópolis: Vozes; 1989.

6. Peruzzo AS, Jung BMG, Soares T, Scarparo HBK . A expressão e a elaboração do luto por adolescentes e adultos jovens através da internet. Estudos e Pesquisas em Psicologia, 2007; 7 (3): 449-461. Disponível em: http://www.revispsi.uerj.br/v7n3/artigos/pdf/v7n3a08.pdf.

7. Ewald AP. Fenomenologia e existencialismo: articulando nexos, costurando sentidos. Estudos e Pesquisas em Psicologia. 2008; 8(2): 149-165. Disponível em: http://pepsic.bvsalud.org/scielo.php?pid=S180842812008000200002\&script=sci_abstrac t.

8. Garcia MC. O existencialismo de Jean Paul Sartre e a pedagogia da autonomia de Paulo Freire [Monografia]. Criciúma: Universidade do Extremo Sul Catarinense; 2008. Disponível em: http://www.cefetsp.br/edu/eso/culturainformacao/paulo_freire_sartre.pdf.

9. Frazão FJR. A perspectiva antropológica do existencialismo. Revista Eletrônica Print by FUNREI. 1999; I(1): 65-68. Disponível em: http://www.ufsj.edu.br/portalrepositorio/File/revistalable/numero1/frazao7.pdf.

10. SANTOS PCF. A atualidade do conceito de angústia de Kierkegaard. Revista da Universidade Vale do Rio Verde, 2011;9 (2): 202-214. Disponível em: http://revistas.unincor.br/index.php/revistaunincor/article/view/271.

11. Sartre JP. O ser e o nada: ensaio de fenomenologia ontológica. Tradução de Paulo Perdigão. 5 ed. Rio de Janeiro: Vozes; 1997.

12. Kierkegaard SA. Diário de um sedutor; Temor e tremor; O desespero humano (Os Pensadores). Tradução de Carlos Grifo, Maria José Marinho, Adolfo Casais Monteiro. São Paulo: Abril Cultural, 1979. Disponível em: http://charlezine.com.br/wpcontent/uploads/2012/10/31-Kierkegaard-Cole\%C3\%A7\%C3\%A3o-Os-Pensadores1979.pdf.

13. Araújo, FPA. O existir do homem. Revista Eletrônica Print by FUNREI. 1999; I(3): 71-74. Disponível em: repositorio/File/revistalable/numero1/fernanda8.pdf. http://www.ufsj.edu.br/portal-

14. SOARES MJ. A angústia como disposição afetiva em Ser e Tempo [Dissertação]. Rio Grande do Sul: Universidade Federal de Santa Maria; 2010. Disponível em: http://w3.ufsm.br/ppgf/wp-content/uploads/2011/10/disserta\%C3\%A7\%C3\%A3o.pdf.

15. WERLE, M. A. A angústia, o nada e a morte em Heidegger. Trans/Form/Ação, 2003; 26 (1): 97-113. Disponível em: http://www.scielo.br/pdf/trans/v26n1/v26n1a04.pdf.

16. Alves R. Do universo à jabuticaba. São Paulo: Planeta do Brasil; 2010.

17. Drawin CR. Angústia e saber: reflexões sobre a inter-relação entre psicanálise e filosofia. Reverso. 2008; 30(56): 15-26. http://pepsic.bvsalud.org/scielo.php?script=sci_arttext\&pid=S010273952008000200002. 
18. SOUZA JJB. Angústia e felicidade na filosofia de Santo Agostinho. Departamento de Filosofia, Ágora Filosófica, 2007; 7 (1): 63-75. Disponível em: http://www.unicap.br/ojs/index.php/agora/article/download/85/79.

19. Stevens B. Não apresse o rio (ele corre sozinho). São Paulo: Summus Editorial; 1978.

20. Camus A. O mito de Sísifo. Tradução de Ari Roitman e Paulina Watch. Rio de Janeiro: Record; 2010.

21. Peres MB, Holanda AF. A noção de angústia na prática clínica: aproximações entre o pensamento de Kierkegaard e a Gestalt-terapia. Estudos e Pesquisas em Psicologia, 2013; 3 (2): 01-15. Disponível em: http://pepsic.bvsalud.org/scielo.php?script=sci_arttext\&pid=S180842812003000200007.

22. Bispo MFM, Rosa RS. O mito de Sísifo:a decisão de viver ou suprimir a vida. Filosofando: Revista de Filosofia da UESB. 2013; 1(2): 18-26. Disponível em: http://periodicos.uesb.br/index.php/filosofando/article/download/2817/4131.

23. TAVERNA, G; SOUZA, W. O luto e as suas realidades humanas diante da perda e do sofrimento. Caderno Teológico da PUCPR, 2014; 2 (1): 38-55. Disponível em: http://www2.pucpr.br/reol/index.php/teologico?dd99=pdf\&dd1=14546.

24. Sesc. A terceira idade: estudos sobre envelhecimento. Gerência de estudos e programas da terceira idade, 2012; $23 \quad$ (53). Disponível em: http://www.sescsp.org.br/files/edicao_revista/cd42b419-7df9-4182-8a574188279cf8a5.pdf.

25. SILVA CS. Contribuições da psicologia existencial no enfrentamento das perdas e da morte [Monografia]. Santa Catarina: Universidade do Vale do Itajaí; 2007. Disponível em: http://siaibib01.univali.br/pdf/Cristiane\%20Soleto\%20da\%20Silva.pdf.

26. Kóvacs MJ. A caminho da morte com dignidade no século XXI. Revista Bioética. 2014; 22 (1): 94-104. Disponível em: http://www.bioetica.org.br/library/modulos/varias_bioeticas/arquivos/Varias_Dignidade.pdf.

27. Marinho AHR, Marinonio CCR, Rodrigues, LCA. O processo de luto na vida adulta decorrente de morte de um ente querido [Monografia]. Rio de Janeiro: Universidade Estácio de Sá; 2007. Disponível em: http://www.4estacoes.com/pdf/publicacoes/o_processo_luto_vida_adulta.pdf.

28. Freitas JL. Luto e fenomenologia: uma proposta compreensiva. Revista da Abordagem Gestáltica. $\quad 2013 ; \quad 19 \quad$ (1): 97-105. Disponível em: http://pepsic.bvsalud.org/scielo.php?script=sci_arttext\&pid=S1809-68672013000100013.

29. Magalhaes MV, Melo SCA. Morte e luto: o sofrimento do profissional da saúde. Revista Psicologia e Saúde em Debate. 2015; 1(1): 65-77. Disponível em: https://psicodebate.files.wordpress.com/2014/12/5-magalhc3a3es-melo-2015.pdf.

30. Borges MAR, Amaral AF. A desigualdade social e suas influências na subjetividade contemporânea. Revista Psicologia e Saúde em Debate. 2015; 1(2): 01-19. Disponível em: https://psicodebate.files.wordpress.com/2015/08/1-borges-e-amaral-2015.pdf. 